\title{
The Impact of Digitalisation and Entrepreneurial Networks on Business Strategy Development—a Media Richness Theory Approach
}

\author{
Thao Orrensalo \\ Åbo Akademi University \\ thao.orrensalo@abo.fi
}

\author{
Maedeh Ghorbanian Zolbin \\ Åbo Akademi University \\ maedeh.ghorbanianzolbin@abo.fi
}

\author{
Shahrokh Nikou \\ Åbo Akademi University \& \\ Stockholm University \\ shahrokh.nikou@abo.fi
}

\begin{abstract}
In the digital-based economy, digitalisation, entrepreneurial networks, and business strategy are three important interdependent components of entrepreneurship process. Accurate, reliable, and timely information is also vital to effective decisionmaking of the entrepreneurs. Often, owing to limitations in their resources and capabilities, entrepreneurs rely on their entrepreneurial networks to satisfy their information need. The core objective of this paper is to examine the use of information in business strategy development and assess the role of entrepreneurial networks as information sources. The theoretical lens used in this narrative literature review is media richness theory. The findings of this paper show that entrepreneurial networks significantly influence entrepreneurial success and survival, and that access to accurate and timely information enhances business strategy development.
\end{abstract}

Keywords: digitalisation, entrepreneurship, entrepreneurial networks, information, media richness theory.

\section{Introduction}

In the light of the benefits associated with entrepreneurship, a growing body of research has explored factors affecting entrepreneurial performance and success. These attempts aim to identify superior ways to best assist the emergent ventures [1]. Several studies have recently outlined the criticality of information as a source of influence and power for entrepreneurial success as well as its survival [1-4]. Entrepreneurs need information to overcome pressure, adapt to market changes, develop their enterprises in the business world, and make the most appropriate decision. The current research shows an increased interest in the importance of information in building ventures and strategy development [3]. But the discussions mostly focus on the usefulness of information rather on the efficiency of entrepreneurs' ability to access information via different information resources, such as the entrepreneurial networks and information retrieval systems. Hence, more study is needed to assess and evaluate how entrepreneurs obtain and use information within their business environment and assess the impact of such behaviours on business strategy development. Moreover, owing to a lack of information infrastructure and resources, entrepreneurs frequently rely on their entrepreneurial networks to acquire information [5-6]. Entrepreneurial networks represent a key resource that facilitates the discovery of critical information and offers valuable opportunities for the entrepreneurs; thus, driving forward the business priorities and operations [7]. Digital disruption has transformed the entrepreneurial approach and the use of entrepreneurial networks for seeking information. Digitalisation enables tie formation and generation of impersonal connections without being necessarily linked to time or place; thus, increasing the value of entrepreneurial social networks at a greater scale and efficiency than ever before [8]. From an academic perspective, understanding of the nuances of entrepreneurial networks, and how they intersect with the entrepreneurs' ability to access information, requires an extensive review of the literature. Scholars benefit from such research since it indicates the extent to which this line of research has been able to uncover and identify the impact of entrepreneurial networks on entrepreneurs' information-seeking behaviours (ISBs). Notably, in the digital age, some researchers argue that digital technologies impact the formation and strength of entrepreneurs' network ties and the flow of information [9-11]. These ties refer to the strength of social ties (weak and strong ties) and exist within interpersonal relationships. Strong ties play an essential role in the sharing of activities concerning information, knowledge, emotions, and experiences [9]. In this paper, we will examine the role of strong and weak ties under the lens of the media richness theory (hereinafter: MRT) [12]. This theory serves as a theoretical lens through which to examine the 
effectiveness of entrepreneurial networks. We chose to focus on this theory as it is based on the premise that the efficiency of performance depends on how closely the information processing requirements match the medium's ability to convey information richness [12].

Considering these cues, the core objective of this paper is to examine the importance of entrepreneurial networks in accessing information and developing business strategies. We ask the following questions:

1: How does access to information influence the development of business strategy?

2: What is the role of entrepreneurial networks in relation to entrepreneurs' ability to access information access and develop business strategy?

3: How has digitisation transformed the nature of entrepreneurial networks?

We answer these research questions through a narrative literature review, with two main aims. First, we aim to provide new knowledge to inform research on entrepreneurs' access to information, which is largely assumed to be significant for their fluent exchange flow of knowledge. Our study focuses primarily on the principles of information access in relation to developing entrepreneurial business strategies, especially within a digital context. Second, we contribute to the literature by providing new understanding of the role that the entrepreneurial networks play in entrepreneurs' accessibility of information and expand this line of discussion by examining the digital disruption through the MRT.

The reminder of this paper is presented as follows. We begin with short discussions on methodology, and strategy development. Then, we present the concepts of entrepreneurial networks and how digitalisation has affected such networks and the relationships within. Finally, we discuss the entrepreneurial networks through the lens of MRT and provide the discussion and conclusion.

\section{Methodology}

Given the explicit focus of the study stated above, we conduct a narrative review to analyse the literature on accessing information via entrepreneurial networks, especially in the digital age. By doing so, we aim to evaluate the importance of information, to entrepreneurs, in terms of developing their business strategies. This methodology allows us to provide an exploratory evaluation of a subset of literature concerning this phenomenon. Furthermore, we chose this approach to maintain the flexibility necessary to investigate the impact of digitalisation on entrepreneurial networks through the lens of MRT. This narrative literature review will be consolidated into a lightweight theoretical framework which supports a later discussion of the research problem. This review looks at studies published in 2020-2021. We start by selecting the relevant publications and articles that highlight the importance of access to information on the formation and development of business strategies. Next, we delve deeper into the literature to better understand how entrepreneurs use their professional networks to access information. We elaborate on this issue by examining the impact of digitalisation on entrepreneurial networks. Digital disruption will be analysed through the strength of ties, and the delivery of information richness with the utilisation of MRT.

\section{Business strategies \& information}

The development and implementation of business strategies are crucial for every organisation to better predict its future, identify its position, understand its level of productiveness both internally and externally, sustain its finance, and utilise its tangible and intangible assets for business advantages [13-15]. Dollinger [78] defined business strategy as patterns of decisions that configure an organisation's internal resources and deploy and guide its business operations in line with the market situation. Other scholars have considered business strategy as a continual engagement with other parties and the formation of a framework in which enterprises establish their meaning and purpose as a result of these interactions [15-16]. According to this assumption, any attempt to manage organisational operations will require a change in focus away from how the organisation distributes and organises its internal resources, to how it relates its activities and resource allocation to other relevant parties. Various forms of business strategy are utilised by different organisations, such as organisational strategy, financial strategy, personnel strategy, technology (ICT) strategy, marketing strategy, customer strategy, service/product strategy, service diversification, rejuvenation communication, and risk management strategy [17-18]. Entrepreneurs and their ventures are living in an ever-changing environment, which is faceless, atomistic, and beyond the authority or control of the organisation. The role of business strategy; therefore, becomes a vital ingredient in determining the future of any organisation. A viable strategy will yield growth and profit regardless of what objectives the managers have established. This statement has been proven by strategy literature through positive links between different strategies and the success of young firms [19-20]. The entire planning strategy involves analysing and understanding the external and internal environment, setting, and describing the vision and mission, 
determining a series of objectives, implementing these objectives through programmes and activities, and finally, measuring the sustainable strategy [14, 21]. The business environment often involves dynamic, complex, and uncontrollable external influences within which entrepreneurs have to function [14]. Thus, scanning the environment, and collecting and processing accurate, reliable, and timely information, can help businesses align their organisations to the turbulent and equivocal environmental conditions, thereby leading to better decisions [22]. In this regard, information is critical for planning and managing an organisation's business strategy. Not only does this help business owners know their environment [3, 14], but also, the acquisitions and effective use of information positively influence business strategies, operations, and performance evaluation [23]. The uncertainty of the business environment stems from the need for timely, accurate, trustworthy, affordable, and relevant information. With quality information, entrepreneurs can proceed with effective decisions for developing their business strategy [24]. In addition, information helps entrepreneurs to better understand the external forces, avoid threats, reduce risks, effectively respond to any changes, and proactively prepare for their long/short-term position in the market. According to Choo [25], a firm's capacity to accurately predict the external changes and incorporate this information and knowledge when developing their business strategy is critical to its survival and success.

\section{Entrepreneurial networks}

In this section, we will discuss entrepreneurial networks as critical resources for business information and the formation and development of business strategy. The literature shows that there is no unified definition for networking. Many scholars, such as Gould and Penley [26], Forret and Dougherty [27], and others, attempted to define it based on its critical role in important issues, such as cooperation or competition [16]. Entrepreneurial networks establish internal and external connections between businesses and other sources within their operational context. Industrial digitalisation puts more emphasis on the interdependence of networks, as these networks have a direct and noticeable effect on the development, improvement, and performance of any business [28]. Nevertheless, these definitions have one thing in common: they all emphasise the importance of networks as a source of information for business need. For a business to achieve success, the accumulation of information resources is the main prerequisite, which could be accomplished via exchanges with other actors in the environment. These actors include different stakeholders, e.g. customers, suppliers, competitors, policymakers, and so on. Gibson et al. [29] stated that entrepreneurial networks provide great opportunities and sources for entrepreneurs to access different information effectively and efficiently. Möller and Halinen [30] argued that a detailed and accurate level of information and knowledge can only be obtained by participating in the activities of entrepreneurial networks or through having relationships and connections with the knowledgeable parties (actors) within the networks since businesses are highly interrelated and correlated through their dependence on mutual resources [15, 31]. They further claimed that without a proper networking strategy with their stakeholders, businesses cannot obtain the necessary information and knowledge to properly manage their activities or futures [30]. In addition, Eikelenboom and Jong [32] revealed the role of entrepreneurial networks in closing having close resource loops and keeping them secured and relevant to any business over time. Entrepreneurial networks are considered a great way to extend the potential resource base for entrepreneurs. By utilising a network, entrepreneurs can gain access to accurate, reliable, relevant, and timely information. This also adds confidence and credibility to the flow of information exchanges among actors [33-34]. In the case of nascent ventures, networks act as a conduit for information, and provide entrepreneurs with essential and critical information, thus improving the opportunities for success, and indeed, venture survival and growth [35]. Furthermore, networking grants and expands entrepreneurs' access to the various sources of information needed for the formation and development of their business strategies [34]. Networking comes with various benefits, especially for those companies which are in the early stages of their business start-up. These benefits include (i) forming strategic alliances, ensuring access to necessary skills, expertise, and sufficient information resources [36], (ii) enhancing entrepreneurs' ability to face uncertainty regarding the future or challenging tasks that they are facing (e.g. by exploiting opportunities, exploring markets, and engaging with customers) owing to the availability of essential information, and (iii) the facilitation and support of effective networking activities, which are of significant magnitude because of the idiosyncrasy of entrepreneurs' initial needs for information [37-38].

\section{Digitalisation and entrepreneurial networks}

Owing to the enhancement and ever-growing demand for utilisation of different digital equipment, 
the business world has increasingly become digitalised [39]. According to [40], digitalisation encourages entrepreneurs to interact with different actors within their network, thus improving their capacity to deal with the complex and rapidly changing economic environments. Digitalisation opens multiple opportunities and benefits - for instance, enhancing entrepreneurial networking. Through these networks, entrepreneurs can access information and knowledge which are more suitable and market-oriented for, innovations and improvements in their products or services [41]. In addition, the use of entrepreneurial [digital] networks provide entrepreneurs with more reliable and relevant information and knowledge communication, thus increasing their opportunities to be involved in different business segments. For instance, many authors have debated the use of digital networks in forming close relations with customers, thus enhancing entrepreneurs understanding of customers' behaviours, preferences, and expectations. This knowledge is utilised to improve the value of the company, offer more creative and innovative contributions, and extend the organisation's reach to different resources at a lower cost. In addition, access to networks in the digital age can further enhance the performance of a company by opening and optimising new revenue streams [42]. Digitalisation significantly influences business networking using social media and online social networking platforms. Current literature [e.g. 8, 43] has reported that digitalisation efficiently assists entrepreneurs in acquiring different knowledge and information to progress the sustainability of their venture and the growth of the business, such as customer information or market asymmetries, and in mobilising resources. Easton and Araujo [18] pointed out that with the aid of digital advancement and digital technology, entrepreneurs can overcome the scarcity of resources (finance, time, effort, human resources) and yet still maintain efficient forms of communication and access the amount of information needed for their business. Digitalisation provides entrepreneurs with sufficient tools to efficiently manage their online relationships and reinforce their offline relationships beyond geographical proximity and at an efficient cost-effectiveness [43-44]. In addition, digitalisation leads to an increase in digital information and the ability to access information in turn structures, shapes and influences our modern market [45]. It benefits businesses by offering a new, efficient way of communicating and networking [4546]. To illustrate, in the digital context, an integrating platform (serving as a bridging node) utilises digitalised networking systems focusing on information subscriptions and transactions. Online communications have served as a novel factor in terms of relationships with the organisational stakeholders, especially end customers [48]. This communication channel serves to establish direct and extensive contact with other parties within the environment and form a digital-based network. Additionally, this type of network helps to establish connections across nations, cities, industrial plants, and business premises [42]. Interestingly, Brennen and Kreiss [49] also examined the digital effects of the convergence of the material infrastructures of communication. Because digital information can be altered and interpreted by any digital system, a single network can transmit any sort of digital signal. The authors concluded that as a result of digitalisation, a single infrastructural network is capable of carrying and conveying information that, in the past, would have been provided by several networks.

\section{Entrepreneurial networks through the analysis of weak and strong ties}

Often an entrepreneurial network is analysed through its ties, including strong and weak ties. The network is made up of groups that are tightly connected internally by both strong ties and weak ties [50]. The strength of those ties is based on different factors, such as the amount of time, emotional intensity, intimacy, and reciprocal services involved. On the one hand, strong ties refer to the close social relationships that one has with others, such as family, friends, or colleagues. Members in strong social ties tend to communicate more frequently and share a great deal of trust in the relationship. Weak ties, on the other hand, are social contacts with whom an individual often have a looser connection, such as acquaintances or a stranger with a common background. This looseness may result from the short duration of the relationship, infrequent interaction, or a personal feeling of a lack of closeness [51]. In strong ties, there are frequent interactions between parties, and such interactions are often based on a high degree of mutual trust [52]. Meanwhile, weak ties involve low levels of trust and reciprocity [42]. Each of the ties serves to extend the network beyond its normal state [53]. Scholars like Krackhardt [54] and Friedkin [55] referred to those strong ties as the dominant ones. Other scholars, such as Granovetter [51], considered weak ties to have more power. Moreover, Rowley et al. [56] argued that both strong and weak ties are equally as effective in terms of enhancing business performance. These two ties are not conflicting. Rather, each of them plays a valuable role in facilitating business activities in the context of different business situations and purposes. They offer distinct benefits and contributions to entrepreneurial 
process [57]. Particularly, weak ties refer to the ties which connect actors to distinct social worlds [58]. They comprise various parts of the social system which are not easily defined. Weak ties are important for entrepreneurial activities [52] as through these ties, entrepreneurs and businesses are more likely to be able to access diffuse information [59]. Weak ties provide accessibility to rich resources information as they offer connections to divergent branches of the network [57]. Moreover, weak ties provide a rich source of different ideas and valuable information, which act as an engine for organisational innovation [59]. In addition, weak ties provide users with information, knowledge, and resources, which are beyond what is available in a close social circle. Scholars have suggested that the growth of weak ties should occur in parallel with the growth of business innovations [58]. Furthermore, the transfer of knowledge and information through weak ties is lower, which makes this form of transfer more efficient than transfer through strong ties [59]. In contrast, strong ties relate to making connections between similar and well-defined people and a better understanding of the actors involved [60]. These ties are more strongly associated with the mutual perspectives, such as trust, emotional support, mutual beliefs, etc., shared within the network. This closeness leads to redundant information and enhances the reinforcement of ideas that emerge through the network interactions [61]. Actors with strong ties are exposed to a mutual willingness to share and exchange information [59]. Such actors can access the exchange of detailed information and tacit knowledge through trust-based governance, and resource cooperation [57].

\subsection{Analysing entrepreneurial networks through the lens of MRT}

According to Dekker and Engbersen [62], digitalisation facilitates both strong and weak ties. In the digital era, the exchange of information is highly reliant on ICTs. Both weak and strong ties without ICTs are at risk of exclusion from information flows [63]. In addition to this phenomenon, scholars have revealed that state-of-art communication tools, such as social network site communications, could assist businesses - especially entrepreneurs - in initiating weak ties and maintaining strong ties in order to launch, grow, and support their ventures [64]. It seems that strong ties are most powerful through offline social networks, while online social networks promote and strengthen weak ties [65]. Digitalisation and technological development provide opportunities for weak ties to thrive further. The development of digital tools and different networking platforms facilitates entrepreneurs' connections to different sources, which were originally not available to them [38]. The MRT has become reputable and popular with the emergence and development of electronic communication media. Frasca and Edwards [66] claimed that the capability of a medium in terms of reproducing and delivering information could be fully explained by this theory. The main concept behind this theory is that each medium can transfer the information required, but its proficiency in delivering and reproducing this information determines the outcomes. The effectiveness of information delivery is reflected through the richness of the communication medium. MRT is rooted between two communication forces: uncertainty and equivocality. Uncertainty indicates that an absence of information occurs when there is a lack of information. Contrastingly, equivocality refers to confusion or lack of understanding arising from ambiguous and conflicting interpretations of media communication. The amount of information is crucial in resolving the receiver's uncertainty, whereas the media's propensity for deliberation, clarification, and enactment helps to reduce ambiguity. According to MRT, the richness of a medium can be determined by considering four aspects: (i) immediate feedback, (ii) multiple cues, (iii) personal focus, and (iv) language used. The effectiveness of a medium in transferring information may be governed by its level of richnessthat is, whether it's a rich or lean medium. Rich media include several means of communication used to transfer and convey specific messages to receivers. As pointed out by Suh [67], these media are suitable for conveying complex messages. Lean media, on the other hand, deliver plainer messages with very little nuance. With lean media, more time is needed to understand a message; thus, it is more suitable for conveying simple and easy information.

Moreover, the use of rich media makes it possible to illuminate obscure issues, thus enhancing the information process by going beyond the various frames of reference. The advantage of this type of medium lies in its ability to transfer gestures to some extent to reduce the level of equivocality. According to MRT, more intricate (uncertain, equivocal, sensitive) messages require the use of richer media, which are linked to strong ties. Daft and Lengel [12] rated face-to-face as the richest medium and underestimated the digital channels, especially in the entrepreneurship context. Vriens and van Ingen [68] argued that social media and strong ties are not an ideal combination. Online conversations are generally brief and straightforward, often displaying an absence of non-verbal cues and physical proximity, which leads to miscommunications. They fail to convey the expression of complex ideas or deep feelings [69], and 
the warmth of face-to-face communication [70]. However, this statement is open to debate. Digitalisation has made significant changes in the ways that people and organisations communicate [71]. In addition, digitalisation has enabled communication through digital mediums to become more interactive and responsive. It allows users to send and receive vast amounts of data instantly, constantly, and globally. With the use of computer-mediated communication methods, communication has evolved into a more visual way for people to exchange information in a way that was previously impractical [72]. Moreover, digitalisation provides the opportunity to overcome physical barriers. It is credited with the potential to break down boundaries concerning nationality, race, language, and ideology [73]. Digital media make it possible for companies to extend their weak ties and expand their relationship with actors in their environment, such as customers, competitors, suppliers, etc. [56]. In addition, in the context of strong ties, the utilisation of digital media is strongly regarded as a means of maintaining relationships [74]. More importantly, communication via digital platforms can take different forms - for example, social networking websites (e.g. Facebook, LinkedIn, Reddit), instant messaging apps (e.g. Zalo, Telegram, Snapchat, WhatsApp, Viber), blogging and microblogging websites (e.g. Twitter, Tumblr, WordPress), photo-sharing social networking apps (e.g. Instagram), and video-sharing platforms (e.g. YouTube). Communications through these digital media have increasingly facilitated the inclusion of social cues (gestures, body languages) in their delivered messages [75]. Digitalisation has also improved the time and effort invested in sending and receiving messages. As an example, a video call through digital platforms (Zoom, Skype, WhatsApp, Teams) allows users to view each other, talk, discuss, and share documents in real time. Users can also send and receive a text instantly as it is typed or created. Many authors have claimed that social media can meet users' desire for instant communication, strengthening trust between the involved parties and enhancing social presence and engagement [76]. These features challenge the assumption that online channels are often leaner - especially when referencing the weak ties network - than face-to-face or interpersonal meetings. Revising MRT, rich media may be defined as comprising four aspects: (i) immediate feedback, (ii) multiple cues, (iii) language variety, and (iv) personal focus [12]. In other words, a rich medium must afford the capacity to allow for, for example, a quick bidirectional communication and a rapid exchange of messages and should enable users to express their personal feelings and tailor messages to suit the needs or situations of receivers. Additionally, a rich medium must provide multiple or comprehensive information patterns, such as emotional expressions, along with the capacity to adjust voice tone and body gestures, for different communication purposes. Through this type of medium, users are then able to express a wide range of meanings conveyed by the available set of symbols in a language. As discussed above, the current state of social media favours its ability to incorporate rich medium features in line with MRT. Therefore, we argue that the utilisation of digital technology and online platforms makes the delivery of rich information possible, thereby enhancing the strength and capability of the networks in terms of the flow of information, especially regarding weak ties. This phenomenon is being developed in parallel with the advancement of digital tools and platforms. These features are being significantly and rapidly developed to improve the interactions, which we used to only receive via in-person forms of communication. MRT thus supports the richness of digital media [77]. Finally, the above discussions highlight the importance of the role of media in the development of entrepreneurial networks and the exchange of critical and much-needed information among entrepreneurs and businesses.

\section{Discussion and Conclusion}

In this paper, we review the literature on business strategy, digitalisation, and entrepreneurial networks. We contribute to the entrepreneurship literature by providing insights into the relationship between the use of, and access to, information through entrepreneurial networks regarding business strategy development. The findings provide answers to the research questions outlined in the introduction section. We exploit and review the literature firstly to demonstrate the impact of entrepreneurial networks on entrepreneurs' ability to access information and secondly to further the development of business strategies by providing the theoretical propositions described below. First, through a narrative literature review, we highlight the importance of information access in shaping business strategies. Excellent performance and business growth do not happen randomly; rather, they are the result of access to accurate, reliable, and timely information, along with proper planning, implementation, and execution of the business strategy. The business environment, especially in the emerging digital economy, is often dynamic and uncertain. Therefore, entrepreneurs need to be able to acquire, analyse, and comprehend information relating to the current circumstances and 
the future evolution of the environment of which they are part of [3, 14, 23-25]. Based on these findings, we introduce the first proposition. P1: "Information is vital for entrepreneurs to plan and develop their business strategies - hence, enhancing the success of their business performance, and growth."

The second contribution of the paper concerns the insights of entrepreneurial network activities as a critical source of information. The findings answer the second research question by highlighting the value of the entrepreneurial networks as an integral part of entrepreneurial success in our information-based economy [29]. The entrepreneurship literature shares the idea that entrepreneurial networks serve as the principal means of identifying and acquiring relevant information sources relating to the business environment [15, 18, 40-48]. In addition, we provide new knowledge on how information access is influenced by the strength of entrepreneurial networks, i.e. through weak and strong ties. Based on the literature, we conclude that both weak and strong ties allow entrepreneurs to access information, and positively relate to entrepreneurial performance and growth $[42,51-52,57,59]$. Based on these findings, we propose the second proposition. P2: "Entrepreneurial networks, including both weak and strong ties, are crucial sources of information for entrepreneurs and their ventures.",

The third research question concerns the changes in the nature of entrepreneurial networks due to the rapid development of digital technologies and platforms. We argue that, in the digital age, entrepreneurs use digital tools and platforms to expand their business networks, to reach customers, and to build business partnerships. The findings of this review also contribute to the discussion on how weak and strong ties work in terms of the way entrepreneurs approach information. We learned that digitalisation has enhanced the effect of weak ties, thus making it more appealing and useful to provide entrepreneurs with opportunities to access information sources more easily [64-65]. We thus propose the third proposition. P3: "Digitalisation facilitates the strength of entrepreneurial networks and positively influences the efficiency of entrepreneurs' access to information."

Finally, through the lens of MRT, we further contemplate the nature of networks under the effect of digitalisation. Digitalisation has enriched the communication channels of digital platforms, thus allowing this channel to fulfil the requirement of a rich medium by meeting four requirements - i.e. immediate feedback, multiple cues, language variety, and personal focus. Based on these features of the digital medium, networks within this context will also be enhanced, thus blurring the barriers between impersonal and interpersonal communication, weak ties, and strong ties. Overall, the findings of the literature review on the nexus between digitalisation and entrepreneurial networks reveal that both elements are critical for the formation and development of business strategies, and that success in the digital age can be achieved by having access to accurate, reliable, and timely information. This literature result inspires our fourth proposition. P4: "Digital developments embrace the power of entrepreneurial networks by eliminating the traditional barriers and enhancing the flow of information and knowledge."

There are also some limitations with this research. Our discussion focuses first on the positive effects of digitalisation, but neglects its negative effects, thus indicating a potential path for other researchers to review and investigate this aspect of digitalisation. The study of negative impact could refer to information overload, misinformation, and the dark side of digital networks - mistrust, distrust, internet fraud, and miscommunication - through the use of digital tools and platforms. Furthermore, through our review, we also acknowledge that scholars have widely discussed the essentials of information access in forming and managing business strategies. Our review of the literature also finds that much research has emphasised the consequences of information access without considering the unfolding nature of this process itself. This limitation in the research suggests other scholars should focus on the entrepreneurial process of information access and the use of this information in developing business strategies. In addition to this research cue, businesses often separate their business strategy into multiple divisions - i.e. marketing strategy, personnel strategy, competitor strategy, etc. Each strategy subdivision will require different information, and the approach to this information might vary. Also, entrepreneurial information needs will continue to evolve. Having established the link between information needs for each strategy, we therefore propose a demand for future research that examines entrepreneurial information-seeking behaviours based on the type of information and the nature of tasks, and the possible situational and societal factors that might influence the entrepreneurs' need for information. Another interpretation is that entrepreneurial success requires the facilitation of both strategic and entrepreneurial networks. Previous research has also examined the relationship between entrepreneurial networks and strategy and the development of this relationship in the ever-changing business environment. We thus suggest that future research should be directed towards observing and investigating any changes in this relationship over time. Based on the findings of this 
research regarding the evolution of entrepreneurial networks through the lens of MRT, future research should further develop the analysis by considering the impact of digitalisation on the richness of information and media, and how these are influenced by the efficiency of the network and its strength. One question emerging from this context relates to the possible redefining of the concept of face-to-face meeting, as nowadays we can see the person we are speaking to through the interface of digital platforms and tools. As we suggested that MRT may have become obsolete, we then propose researchers in the field should turn their attention to examining the relevance and importance of this theory in the digital realm. The study of networks in relation to MRT could be substantiated with empirical research. Researchers should also analyse any factors that could potentially foster and hinder entrepreneurial networks as well as the strengthening of network ties. The desire to consider the value of digital networks from the perspective of their level of media richness may be an important mechanism for promoting positive adoption and performance outcomes from the use of such networks. Lastly, in order to adapt and take advantage of digitalisation in relation to developing business strategies and networks, entrepreneurs need to be equipped with 21 st-century skills, such as digital literacy and information literacy skills and capabilities. Future research should thus be directed towards identifying the different skills and knowledge that entrepreneurs need to work and develop in the digital age, as well as the extent to which the efficacy of these competencies influences entrepreneurs' adoption of these digital advancements.

\section{Acknowlegement}

The first and second authors would like to thank Liikesivistysrahasto \& Åbo Akademi University for their generous financial support.

\section{References}

[1] D.F. Kuratk, "Corporate Entrepreneurship 2.0: Research Development and Future Directions", Foundations and Trends in Entrepreneurship, 13(6), 2017, pp. 441-490.

[2] A. Groşanu, C. Boța-Avram, P.R. Răchişan, R. Vesselinov and A. Tiron-Tudor, "The Influence of Country-Level Governance on Business Environment and Entrepreneurship: A Global Perspective", Amfiteatru Economic, 17(38), 2015, pp. 60-75.

[3] A.C. Cooper, T.B. Folta and C. Woo, "Entrepreneurial information search", Journal of Business Venturing, 10(2), 1995, pp. 107-120.

[4] P.A. Julien and C. Ramangalahy, "Competitive strategy and performance of exporting SMEs: An empirical investigation of the impact of their export information search and competencies", Entrepreneurship Theory and Practice, 27(3), 2003, pp. 227-245.

[5] E. Auster and C.W. Choo, "How senior managers acquire and use information in environmental scanning", Information Processing \& Management, 30(5), 1994, pp. 607-618.

[6] D.P. Soetano, "Networks and entrepreneurial learning: coping with difficulties", International Journal of Entrepreneurial Behaviour \& Research, 23(3), 2017, pp. 547-565.

[7] M. Varis and H. Littunen, "Types of innovation, sources of information and performance in entrepreneurial SMEs", European Journal of Innovation Management, 13(2), 2010, pp. 128-154.

[8] J. Cenamor, V. Parida and J. Wincent, "How entrepreneurial SMEs compete through digital platforms: The roles of digital platform capability, network capability and ambidexterity", Journal of Business Research, 100, 2019, pp. 196-206.

[9] R. Zolin, A. Kuckertz and T. Kautonen, "Human Resource Flexibility and Strong Ties in Entrepreneurial Teams". Journal of Business Research, 64(10), 2011, pp.1097-1103.

[10] M.L. Doerfel and P.J. Moore, "Digitizing Strength of Weak Ties: Understanding Social Network Relationships through Online Discourse Analysis", Annals of the International Communication Association, 40(1), 2016, pp. 127-148.

[11] C. Lee and R. Hallak, "Investigating the effects of offline and online social capital on tourism SME performance: A mixed-methods study of New Zealand entrepreneurs", Tourism management, 80, 2020, p. 104128.

[12] R. Daft and R. Lengel, "Organizational Information Requirements, Media Richness and Structural Design”, Management Science, 32(5), 1986, pp. 554571.

[13] E. Baraldi, R. Brennan, D. Harrison, A. Tunisini and J. Zolkiewski, "Strategic thinking and the IMP approach: A comparative analysis", Industrial Marketing Management, 36(7), 2007, pp. 879-894.

[14] J. Bryson, "Managing Information Services: A Sustainable Approach", Ashgate Publishing, $3^{\text {rd }}$ ed, 2011.

[15] H. Håkansson and I. Snehota, "No business is an island: The network concept of business strategy", Scandinavian journal of management, 5(3), 1989, pp. 187-200.

[16] S.C. Henneberg, S. Mouzas and P. Naudé, "Network pictures: concepts and representations", European Journal of Marketing, 40(3/4), 2006, pp. 408-429.

[17] A. Bharadwaj, O. El Sawy, P. Pavlou and N. Venkatraman, "Digital Business Strategy: Toward a Next Generation of Insights", MIS Quarterly, 37(2), 2013, pp. 471-482.

[18] G. Easton and L. Araujo, "Evaluating the impact of B2B e-commerce: a contingent approach", Industrial Marketing Management, 32(5), 2003, pp. 431-439. 
[19] G.C. Reid and J.A. Smith, "What Makes a New Business Start-up Successful?", Small Business Economics, 14(3), 2000, pp. 165-182.

[20] W.R. Sandberg and C.W. Hofer, "Improving new venture performance: The role of strategy, industry structure, and the entrepreneur", Journal of Business Venturing, 2(1), 1987, pp. 5-28.

[21] M. Ropianto, K. Rukun, B. H. Hayadi, F.H. Utami and O. Candra, "Optimization of Strategic Planning Organization in the Framework of Achievement Objectives of Education". Advances in Social Science, Education and Humanities Research (ASSEHR), 2nd International Conference on Education, Science, and Technology, 149, 2017, pp. 149-151.

[22] H. Haase and M. Franco, "Information sources for environmental scanning: Do industry and firm size matter?", Management Decision, 49(10) 2011, pp. 1642-1657.

[23] S. Nikou, M. Brännback, T.P. Orrensalo and G. Widén, "Social Media and Entrepreneurship: Exploring the Role of Digital Source Selection and Information Literacy". In: Understanding Social Media and Entrepreneurship, Springer, Cham, 2020.

[24] S. C. Eze, S. Olatunji, V.C. Chinedu-Eze and A.O. Bello, "Key success factors influencing SME managers' information behaviour on emerging ICT (EICT) adoption decision-making in UK SMEs", The Bottom Line, 31(3/4), 2018, pp. 250-275.

[25] C.W. Choo, "Environmental scanning as information seeking and organizational learning", Information Research, 7(1), 2001, 1-14.

[26] S. Gould and L.E. Penley, "Career strategies and salary progression: A study of their relationships in a municipal bureaucracy", Organizational Behaviour \& Human Performance, 34(2), 1984, pp. 244-265.

[27] M.L. Forret and T.W. Dougherty, "Networking Behaviors and Career Outcomes: Differences for Men and Women?", Journal of Organizational Behaviour, 25(3), 2004, pp. 419-437

[28] J. Nagy, J. Oláh, E. Erdei, D. Máté and J. Popp, “The Role and Impact of Industry 4.0 and the Internet of Things on the Business Strategy of the Value ChainThe Case of Hungary", 10(10) Sustainability, 2018, p. 3491.

[29] C.H. Gibson, H. Hardy and M. Ronald Buckley, "Understanding the role of networking in organizations", Career Development International, 19(2), 2014, pp. 146-161.

[30] K.K. Möller and A. Halinen, "Business relationships and networks: Managerial challenge of network era", Industrial marketing management, 28(5), 1998, pp. 413-427.

[31] G.S.Day and P. Nedungadi, "Managerial Representations of Competitive Advantage", Journal of Marketing, 58(2), 1994, pp. 31-44.

[32] M.Eikelenboom and G.D. Jong, "The Impact of Managers and Network Interactions on the Integration of Circularity in Business Strategy", Organization \& Environment , 2021, pp. p.108602662199463.
[33] A.C. Cooper, "Network, alliances and entrepreneurships". In: M. Hitt, D. Ireland, M. Camp, and D. Sexton (Ed.), Strategic Entrepreneurship. Blackwell, Oxford, 2002, pp. 203- 220.

[34] M.S. Minai, Y. Ibrahim and K.L. Kheng, "Entrepreneurial Network in Malaysia: Are There Any Differences Across Ethnic Groups?", Journal of Business and Policy Research, 7(1), 2012, pp. 178 - 192.

[35] S. Jack, S. Moult, A.R. Anderson and S. Dodd, "An entrepreneurial network evolving: Patterns of change", International Small Business Journal, 28(4), 2010, pp. 315-337.

[36] W. Lamine, A. Fayolle, S. Jack and J. Byrne, "The role of materially heterogeneous entities in the entrepreneurial network", Industrial Marketing Management, 80, 2017, pp. 99-114.

[37] T. Elfring and W. Hulsink, "Networking by entrepreneurs: Patterns of tie-Formation in emerging organizations", Organization Studies, 28(12), 2007, pp. 1849-1872.

[38] D. Soetanto, "Networks and entrepreneurial learning: coping with difficulties", International Journal of Entrepreneurial Behaviour \& Research, 23(3), 2017, pp. 547-565.

[39] S.L. Woerner and B. H. Wixom, B. H. "Big data: extending the business strategy toolbox", Journal of Information Technology, 30(1), 2015, pp. 60-62.

[40] M. Pagani and C. Pardo, "The impact of digital technology on relationships in a business network", Industrial Marketing Management, 67(67), 2017, pp. 185-192

[41] T. Ritter and H.G. Gemünden, "The impact of a company's business strategy on its technological competence, network competence and innovation success", Journal of Business Research, 57(5), 2004, pp. 548-556.

[42] E. Beqiri, "The implications of information networking at the pace of business development", International Journal of Knowledge, 27, 2018, pp. 17-22.

[43] W. Wang, Q. Liang, R.V. Mahto, W. Deng, and S.X. Zhang, "Entrepreneurial entry: The role of social media", Technological Forecasting and Social Change, 161, 2020, p.120337-120337.

[44] Y.Y. Lee, M. Falahat, and B.K. Sia, "Impact of Digitalization on the Speed of Internationalization". International Business Research, 2019, pp. 1-11.

[45] T. Rittera, and G.L. Pedersen, "Digitization capability and the digitalization of business models in businessto-business firms: Past, present, and future", Industrial Marketing Management, 86, 2019, pp. 180- 190.

[46] P.Parviainen, M. Tihinen, J. Kääriäinen and S. Teppola, "Tackling the digitalization challenge: how to benefit from digitalization in practice", International Journal of Information Systems and Project Management, 5(1), 2017, pp. 63-77.

[47] T. Elkjaer and J. Damgaard, "How Digitalization and Globalization have Remapped the Global FDI Network", 16th Conference of IAOS. OECD, 2018, 291. http://www.oecd.org/iaos2018/. 
[48] S.M. Cooper, "Stakeholder communication and the Internet in UK electricity companies", Managerial Auditing Journal, 18(3), 2003, pp. 232-243.

[49] J.S. Brennen and D. Kreiss, "Digitalization", The International Encyclopaedia of Communication Theory and Philosophy, 2016, pp. 1-11.

[50] M. Van der Leij and S. Goyal, "Strong Ties in a Small World”, Review of Network Economics, 10(2), 2011, pp. 1-20.

[51] M.S. Granovetter, "The strength of weak ties", American Journal of Sociology, 78(6), 1973, pp. 1360-1380.

[52] C. E. Villanueva, A. Angeles and L. C. Revilla, "Tying strong ties in informal entrepreneurship: A constraint or an entrepreneurial driver?", Journal of Developmental Entrepreneurship, 23(1), 2018, pp. 119.

[53] E. Brown, "Strong and Weak Ties: Why Your Weak Ties Matter", Social Media Today, 2011 June 30. https://www.socialmediatoday.com/content/strongand-weak-ties-why-your-weak-ties-matter.

[54] D. Krackhardt, "The Strength of Strong Ties: The Importance of Philos in Organizations", Networks in the Knowledge Economy, 1992, pp. 216- 239.

[55] N.E. Friedkin, "Information Flow Through Strong and Weak Ties in intra organizational Social networks", Social Networks, 3(4), 1982, pp. 273-285.

[56] T. Rowley, D. Behrens and D. Krackhardt, "Redundant Governance Structures: An Analysis of Structural and Relational Embeddedness in the Steel and Semiconductor Industries", Strategic Management Journal, 21(3), 2000, pp. 369-386.

[57] T. Elfring and W. Hulsink, "Networks in Entrepreneurship: The Case of High-technology Firms", Small Business Economics, 21(4), 2003, pp. 409-422.

[58] M. Baer, "The strength-of-weak-ties perspective on creativity: A comprehensive examination and extension", Journal of Applied Psychology, 95(3), 2010, pp. 592-601.

[59] C.C. Wang, H.Y. Sung, D.Z. Chen and M.H. Huang, "Strong ties and weak ties of the knowledge spillover network in the semiconductor industry", Technological Forecasting and Social Change, 118, 2017, pp. 114-127.

[60] R. Leonard and J. Onyx, "Networking Through Loose and Strong Ties: An Australian Qualitative Study", VOLUNTAS: International Journal of Voluntary and Non-profit Organizations, 14(2), 2003, pp. 189-203.

[61] S. Valenzuela, T. Correa and H. Gil de Zúñiga, "Ties, Likes, and Tweets: Using Strong and Weak Ties to Explain Differences in Protest Participation Across Facebook and Twitter Use", Political Communication, 35(1), 2017, pp. 117-134.

[62] R. Dekker and G. Engbersen, "How social media transform migrant networks and facilitate migration", Global Networks, 14(4), 2014, pp. 401-418.

[63] I. Boas, "Environmental change and human mobility in the digital age", Geoforum, 85, 2017, pp. 153-156.

[64] C. Smith, J.B. Smith and E. Shaw, "Embracing digital networks: Entrepreneurs' social capital online",
Journal of Business Venturing, 32(1), 2017, pp. 1834.

[65] H. Hu, L. Wang, L. Jiang and W. Yang, "Strong ties versus weak ties in word-of-mouth marketing", BRQ Business Research Quarterly, 22(4), 2019, pp. 245256.

[66] K.J. Frasca and M. R. Edwards, "Web-based corporate, social and video recruitment media: Effects of media richness and source credibility on organizational attraction", International Journal of Selection and Assessment, 25(2), 2017, pp. 125-137.

[67] S.K. Suh, "Impact of communication medium on task performance and satisfaction: an examination of media-richness theory", Information and Management, 35(3), 1999, pp. 295-312.

[68] E Vriens and E. Van Ingen, "Does the rise of the Internet bring erosion of strong ties? Analyses of social media use and changes in core discussion networks", New Media \& Society, 20(7), 2017, pp. 2432-2449.

[69] E. Gilbert, K. Karahalios and C. Sandvig, "The Network in the Garden: Designing Social Media for Rural Life", American Behavioral Scientist, 53(9), 2010, pp. 1367-1388.

[70] P.S.N. Lee, L. Leung, V. Lo, C. Xiong and T. Wu, "Internet Communication Versus Face-to-face Interaction in Quality of Life", Social Indicators Research, 100(3), 2011, pp. 375-389.

[71] E. Cristobal-Fransi, Y. Montegut-Salla, B. Ferrer-Rosell and N. Daries, "Rural cooperatives in the digital age: An analysis of the Internet presence and degree of maturity of agri-food cooperatives' e-commerce", Journal of Rural Studies, 74, 2019, pp. 55-66.

[72] J.W. Treem, P. M. Leonardi, and B. V. D. Hooff, "Computer-Mediated Communication in the Age of Communication Visibility", Journal of ComputerMediated Communication, 25(1), 2020, pp. 44-59.

[73] M. Tanis and T. Postmes, "Social Cues and Impression Formation in CMC", Journal of Communication, 53(4), 2003, pp. $676-693$.

[74] N. Pennington and J.A. Hall, "Does Facebook-enabled communication influence weak-tie relationships over time? A longitudinal investigation into mediated relationship maintenance", Communication Monographs, 88(1), 2020, pp. 48-70.

[75] M.A. Bindrees, R.J. Pooley, I. Al-skloul Ibrahim and N. Taylor, "Re-Evaluating Media Richness Theory in Software Development Settings", Journal of Computer and Communications, 2(2), 2014, pp. 3751.

[76] G. Appel, L. Grewal, R. Hadi and G.T. Stephen, "The future of social media in marketing", Journal of the Academy of Marketing Science, 48(1), 2020, pp. 79 95.

[77] F.C. Tseng, T. C. E. Cheng, P. L. Yu, T. L. Huang, and C. I. Teng, "Media richness, social presence and loyalty to mobile instant messaging", Industrial Management and Data Systems, 119(6), 2019, pp. 1357-1373.

[78] M. Dollinger, "Entrepreneurship", 2008, Marsh Publications. 